\title{
Selection, design and dissemination of Fuerteventura's projected tourism image (Canary Isles)
}

\author{
A. J. Rodríguez ${ }^{1}$, P. Díaz ${ }^{2}$, D. Ruiz-Labourdette ${ }^{2}$, F. D. Pineda ${ }^{2}$, \\ M. F. Schmitz ${ }^{2} \&$ A. Santana ${ }^{1}$ \\ ${ }^{1}$ La Laguna University, Spain \\ ${ }^{2}$ Complutense University of Madrid, Spain
}

\begin{abstract}
Tourism constitutes an important factor among those influencing sociocultural change in populations, particularly when these inhabit tourist destinations. Among the multiple components of the tourism system, the processes of selection, design and implementation of the 'constructed image' are highly valuable with regard to studying the significance and resignificance of the territory. The present study analyses these processes through images presented in brochures and websites relating to the tourism offer of the island of Fuerteventura (Canary Isles). It can currently be observed that the local administrations of this island are attempting to project Fuerteventura's image through its re-adaptation and differentiation as a tourist destination. The process gives rise to contradictions in the selection strategies and significance of the tourism resources between the different administrations and the other actors responsible for 'generating an image'.
\end{abstract}

Keywords: brochures, projected image, symbolic transfiguration, tourism, tourist destinations, websites.

\section{Introduction}

Tourism clearly constitutes a leading activity in international, national and domestic economies. Consensus exists regarding the importance of the tourism image as a motor thereof. Only one other topic, the impacts of tourism, competes with this activity with regard to analysis by researchers. 
Baloglu and McCleary [1] have developed numerous studies on the impact of visits, familiarity of the image, the relationship between the geographic location of the tourist and the perceived image, measurement of the image of the destination, components and factors influencing this, difference between the tourist's image (impression) and the image projected by the destination, or variations in the image depending on the purpose of the visit, among other objects studied. Gallarza et al. [2] or Frías et al. [3] have reviewed this theme.

Through the creation and dissemination of images, the tourism system fulfils its role as an agent of significance and resignificance of a determined territory, and this system therefore becomes an active agent in the reconstruction of the image of the landscape. Generation of a high percentage of tourist destinations depends more upon images than on the 'real characteristics' of the space visited, the tourism industry thus creating a reinvented landscape, both for investors and for tourists.

On the occasion of the Fuerteventura natural resources management plan for the creation of a National Park on the island, the present paper shows a part of the processes of territorial resignificance being studied by our team. The task focuses on the projected image of Fuerteventura as a tourist destination, appraising the strategies by enterprises and administrations in the creation of brochures and websites.

\section{Theoretical framework}

Tourist destinations require strategies for communicating their 'values' as elements of tourist attraction. These values are incorporated into a projectable image and are subjected to a symbolic and aesthetic transfiguration. It is highly likely that an image can condition the decision to travel to one destination or another. Not to mention the possible effects of these actions on resident populations, the process of design and communication of an image is an extremely delicate task.

Study of these circumstances has been addressed by means of static and dynamic approaches, depending on how one examines the relationships between image and tourist behaviour or whether one is dealing specifically with the character of the territory and its inhabitants, respectively. Um and Crompton [4], Gartner [5] and Gallarza et al. [2] consider image as a complex and subjective conceptual construction (Bigne et al. [6]) that combines the consumer's emotions and reasoning with his experience and knowledge of the destination; that is, a 'cognitive component' deriving from mental representations and beliefs regarding the physical attributes of the destination combined with the appraisals and feelings this arouses ('emotional component'; Baloglu and Brinberg [7]). This way of studying tourism is based upon a changing conception of image, focussing on the above mentioned attributes of the destination and on the perception of the consumer-tourist, who is considered to create from all of this a photogram charged with sensibilities, emotions and evaluations (San Martín Gutiérrez et al. [8]). This is, then, an individualised image (Hunt [9]), determined 
by the activeness-passiveness of all tourists (Mercille [10]). In practice, the dynamics generated by the consumer-tourist are used in marketing strategies.

Analysis of the image can also adopt a perspective that includes the actors involved in the design, shaping and transmission of the destination's imaginary such as the local and resident population, institutions, politicians, entrepreneurs and investors, tour operators and retailers- who project a unique image of their area in the construction of the destination's identity. Thus, some elements participating in the tourism system are culture, the personality and character of the territory, traditions, history, beliefs, language, etc., all of which characterise the destination as something unique ('uniqueness'), or making it stand out above others. Indeed, in the tourism system, this image is what culturally shapes the destination and determines to a great extent the visitor's degree of satisfaction and his memory of the visit. Furthermore, the sociocultural effects on local populations of images that are alien to themselves appear in the medium term, modifying patterns, behavioural features and values and reconstructing local identities (Franklin and Crang [11]; Rodríguez Darias [12]).

The systemic approach requires global consideration of the image, and differentiation between the conception, design and implementation of an image constructed for commercial purposes, and the processes of perception an interiorisation. The former deals with the habitual marketing campaigns in areas of demand and destination -actions aimed at promoting coincidence between what has been advertised and what is available, improvement of the profiles presented for each consumer typology, etc. The latter corresponds to individual 'creation' and comparison.

Development of tourism currently calls for outlines and models of research in the double aspect of processes subjected to feedback and interconnected ones, albeit operatively divisible with regard to analysis and implementation. These processes differentiate the 'people's own image' -ways in which the local population perceives itself and its environment-, the 'projected' one constructed, promoted and recreated by tour operators-, the 'perceived' one and the 'remembered' one (Santana Talavera [13]).

Focused on real image and on the projected one, the above mentioned image reconfiguration processes aimed at commercialisation are usually determined by the interests of the institutions and entrepreneurs of the area and, to a certain degree, of the residents. One can usually find three strategies, limited in varying degrees, for construction of this image: $i$ ) a joint policy, participatory and collaborative, involving all or some of those involved in the design of the image (direct actors at the destination) and in the selection of attributes and conjunction of products and their physical and emotional references to the destination's identity; ii) a more or less interested selection, created around products and activities available in the area, grouped according to thematic blocks or subterritorial areas and iii) a conglomerate of more or less compatible initiatives that tend to value attributes of the destination as resources, imagining the demand.

Based upon the people's own ('real') image, in the present paper we refer to two elements of the projected image of Fuerteventura: attracting the client and providing information by means of brochures and websites. By analysing these, 
we attempt to establish which of the aforementioned strategies is most relevant on this island, considering the possible problems involved in their implementation.

\section{Method}

i) We conducted 341 questionnaires in Fuerteventura airport (July to October, 2008); among other themes, they contained items on the reasons for visiting the island and on the use and importance of the technology available in the places of accommodation. The data were completed with information from ISTAC 20002006, 2008 [14]. ii) We systematically reviewed 38 websites on tourism selected according to their public Google rank. Among those mentioning 'Fuerteventura tourism', in April 2009 we selected those with a rank equal to or higher than 2 over a maximum rank of 10 (a total of 31 links); the seven remaining ones corresponded to web pages of the municipalities and Council of the island, very much involved in the image creating processes. iii) We randomly collected (Glasser and Strauss [15]) 146 commercial brochures relating to Fuerteventura. We compiled all those existing in November 2008 and February 2009 into different spaces selected for their representativeness as information zones and due to the amount of users. The Fuerteventura tourism fair stand (FITUR'S 2009) along with the tourism nuclei of Costa Calma and Caleta de Fuste on this island, provided a great deal of information.

Data analysis involved coding of the brochures and websites by means of contents analysis files. The data were standardised with criteria of repeatability, measurability and comparativeness and were tabulated (Díaz et al. [16]; SPSS 17 software). Moreover, together with participant observation as a basic technique we also conducted (June and November, 2008) 21 detailed interviews with whom we considered to be key informing subjects (locals, residents and visitors), who subsequently helped us to understand and interpret data and results.

\section{Results and discussion}

The item of the questionnaire 'how did you get to know Fuerteventura as a tourist destination?' shows that the brochures still work $(22.87 \%$ of the interviewees were thus informed), although Internet (45.16\%), recommendations by family and friends and travel agencies scored far higher.

The reasons of the tourists for their visit $(1,029,502$ visitors in 2008, ISTAC 2000-2006, 2008 [14]) highlight the most noteworthy items as 'climate' and 'the beach', 'nature and landscape', 'price' and 'local culture' (folklore and traditions; Table 1) falling far behind. The interviews also showed a high degree of coincidence in the importance given to sun and the natural quality (not of services) of the beaches, and we found that residents, as opposed to nationals or people from the peninsula, show greater appreciation of tranquility and landscape than the locals, rather than customs and traditions, with the exception of some folklore. Locals and residents from other islands particularly value local 
Table 1: Reasons expressed by the visitors in the survey for visiting the island of Fuerteventura.

\begin{tabular}{|c|c|c|}
\hline Reason for the visit & $\mathrm{N}(341)$ & $\%$ \\
\hline Climate & 325 & 95.3 \\
\hline Beaches & 296 & 86.8 \\
\hline Nature and landscape & 111 & 32.6 \\
\hline Folklore and traditions & 6 & 1.8 \\
\hline Price & 99 & 29 \\
\hline Business & 9 & 2.6 \\
\hline Visiting family or friends & 23 & 6.7 \\
\hline Safety & 24 & 7 \\
\hline Cultural offer & 4 & 1.2 \\
\hline Nightlife & 4 & 1.2 \\
\hline Shopping & 14 & 4.1 \\
\hline Other & 31 & 9.1 \\
\hline
\end{tabular}

cultural elements associated with practices considered to be 'ancestral' and which are beginning to represent serious environmental impacts (camping by the seaside, seafood collection, fishing, etc.); but they reject the idea of regulating these activities linked to natural services.

The data presented in Table 1 contrast with those from the 2000-2006 series of ISTAC 2000-2006, 2008 [14] in its section on 'reasons for the visit'. Furthermore, a gradual increase has been noted in tourist's interest for cultural heritage and landscapes. With regard to the websites and brochures analysed, the communication provided by Internet appears to be modifying the contact between people interested in travelling (pre-tourists) and the offer made from the destinations. Figure 1 presents the percentage of websites analysed presenting

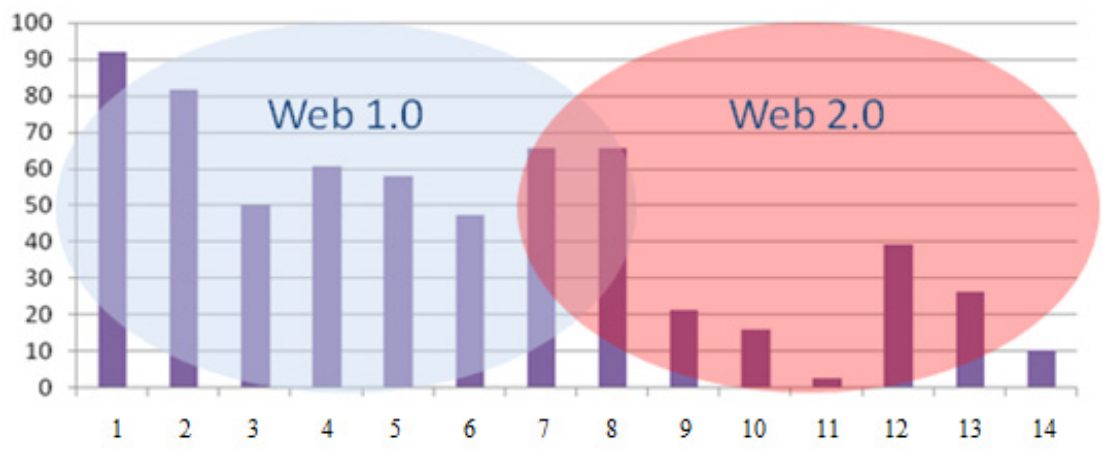

Figure 1: Percentage of websites analysed presenting materials and utilities, which are indicated. 1. contact; 2. links; 3. suggestions; 4. useful tips; 5. search engine; 6. climatology; 7. maps, 8. downloadable catalogues; 9. interactivity; 10. design a la carte; 11 . travel log; 12. virtual graphic materials; 13. online-video/audio; 14. downloadable video/audio. 
determined materials and utilities. The graph shows that Fuerteventura's websites do not respond to the '2.0 tourism' tendency. Aspects such as interactivity, design a la carte, online travel log and downloadable materials are as yet beyond their possibilities. The 2.0 tourism model is a novel form of interaction based upon information technologies facilitating relationships in virtual social networks and interactivity among pre-tourists, tourists and ex tourists, and among entrepreneurs, destinations, populations and other creators of contents. Circumstance can constitute a new conditioning factor of the projected image as, on one hand, it can be adapted to each consumer profile (according to characteristics and demands) and, on the other, it can force the destination as a whole (and the entrepreneurs competing therein) to renovate their techniques more rapidly that they have done to date.

Molina and Agueda [17] have shown that the visitor perceives how the image informing him of the destination's potential values or products presents a high level of heterogeneity, as well as errors in the design of brochures (promoters tend to pay more attention to the amount of brochures printed and distributed than to the quality of their design and contents). On the contrary, in the case of images projected over the web, the demand for quality is greater: what is valued here are access times, design and ease of interaction, capacity to combine contents, intervals of updates of the website, etc., as well as the software the user avails of. The general perception of this format is very favourable and users demand not only information but also downloads of the product or destination (graphic material, videos, screensavers, sound, etc.) that are unavailable in brochure format.

Table 2 shows that one single support of the projected image, whether this be website or brochure, can simultaneously communicate several references, that each support offers many different multiproduct possibilities and collaborative actions among enterprises that are directly or indirectly involved in tourism, and

Table 2: Contents of the analysed set of brochures and websites aimed at tourism on the island of Fuerteventura $(\mathrm{N}$ is the number of elements analysed. It does not represent the sum of values in each column, as one same brochure or website can simultaneously present several contents; moreover, a brochure and a website can both refer to the same content).

\begin{tabular}{|c|c|c|c|c|}
\hline \multirow{2}{*}{ References } & \multicolumn{2}{|c|}{ Brochures } & \multicolumn{2}{c|}{ Websites } \\
\cline { 2 - 5 } & $\mathrm{N}(146)$ & $\%$ & $\mathrm{~N}(38)$ & $\%$ \\
\hline Administration & 27 & 18.49 & 9 & 23.68 \\
\hline Accommodation & 29 & 19.86 & 26 & 68.42 \\
\hline Restaurants & 31 & 21.23 & 12 & 31.58 \\
\hline Complementary activities & 23 & 15.75 & 27 & 71.05 \\
\hline Vehicle rental & 3 & 2.05 & 15 & 39.47 \\
\hline Other types of businesses & 30 & 20.55 & 2 & 5.26 \\
\hline Real estate & 3 & 2.05 & 5 & 13.16 \\
\hline
\end{tabular}


Table 3: Classification of data provided by brochures and websites on Fuerteventura according to the type of tourism classification based upon the image projected by the Administration and other promoters ( $\mathrm{N}$ represents in an undifferentiated manner the total of websites or brochures falling in the categories indicated according to their promoter; see Table 2).

\begin{tabular}{|c|c|c|c|c|}
\hline Type & \multicolumn{2}{|c|}{ Administration } & \multicolumn{2}{c|}{ Others } \\
\hline & $\mathrm{N}(32)$ & $\%$ & $\mathrm{~N}(152)$ & $\%$ \\
\hline Sun and sand & 3 & 9.38 & 86 & 56.58 \\
\hline Cultural & 21 & 65.63 & 20 & 13.16 \\
\hline Nature & 5 & 15.63 & 12 & 7.89 \\
\hline Sports & 4 & 12.50 & 21 & 13.82 \\
\hline Health & 1 & 3.13 & 12 & 7.89 \\
\hline Rural & 2 & 6.25 & 8 & 5.26 \\
\hline Gastronomy & 2 & 6.25 & 5 & 3.29 \\
\hline Undifferentiated T. S. & 1 & 3.13 & 33 & 21.71 \\
\hline
\end{tabular}

that those working in accommodation, the restaurant business or complementary activities constitute recurring and similar references in both supports (brochures: 56.84\%; websites: $67.7 \%$ ). There is a more noteworthy difference in the reference to the Administration in both formats $(23.68 \%$ on the web and $18.49 \%$ in brochures) and a high percentage of brochures (20.55\%) related to other types of tourism businesses that hardly appear on the Internet $(5.26 \%)$.

Without a basic established typology apparently guided by the interests of the promoters, the brochures and websites studied can be framed within a wide range of tourism macro-products (Table 3): sun and sand tourism (climatic), cultural, nature, sports, health, rural, gastronomy and a broad range of tourism services, The data obtained show a clear difference between the brochures and websites produced by the administrations and the other entities generating image. It seems that the administrations show a different kind of social compromise, on promoting cultural tourism, whereas the remaining actors exhibit a more pragmatic consumerism, dealing with sun and sand tourism (sports tourism has been considered separately from cultural tourism). Also standing out is the item 'undifferentiated tourism services', which is mostly associated with what is termed 'other types of tourism business'. Many brochures referring to this type of business fall within this category. This appears to indicate the importance of small and large business initiatives arising in relation to destinations and which cover determined basic needs of visitors (health clinics, shopping centres, gymnasiums, laundries, etc.), filling the gaps sometimes left by the administrations in the planning and management of destinations.

With regard to the objective market, there is clearly little differentiation between the brochures and websites generated by the administrations and by the other promoters. No notable percentage refers to one specific segment (Table 4). 
Table 4: Classification of data provided by brochures and websites on Fuerteventura according to the segment of potential users to whom the image is directed by the Administration and other promoters $(\mathrm{N}$ represents in an undifferentiated manner the total of websites or brochures falling in the categories indicated according to their promoter; see the previous tables).

\begin{tabular}{|c|c|c|c|c|}
\hline & \multicolumn{2}{|c|}{ Administration } & \multicolumn{2}{c|}{ Others } \\
\hline & $\mathrm{N}^{*}(32)$ & $\%$ & $\mathrm{~N}(152)$ & $\%$ \\
\hline Families & 5 & 15.63 & 33 & 21.71 \\
\hline Young people & 5 & 15.63 & 31 & 20.39 \\
\hline The elderly & 0 & 0.00 & 5 & 3.29 \\
\hline Resident families & 0 & 0.00 & 4 & 2.63 \\
\hline Elderly residents & 0 & 0.00 & 1 & 0.66 \\
\hline Undifferentiated & 22 & 68.75 & 81 & 53.29 \\
\hline
\end{tabular}

The brochures relating to 'other types of businesses' are the ones that mostly present this characteristic $(68.75 \%$ of the materials produced by this type of promoters does not refer to a specific segment).

Establishing a generic model of the public, real or symbolic, appears to seen as very difficult in the design of these materials, as it is considered that there will be different perception of the messages issued according to the interests and capacities of each group. Furthermore, this would define the type of iconography, the text contained in the messages referring to the image and their correlation with the slogan chosen. A total of $47.26 \%$ of the brochures and $81.58 \%$ of the website refer specifically in their contents (texts or photographs and illustrations) to elements of heritage, reaching $100 \%$ in the specific case of the images the administrations attempt to project.

The type of heritage referred to by the different promoters are notoriously different (Table 5). Local administrations present the image of this island as a space defined by its culture -handicrafts, museums, rural heritage such as mills, terraces (gavias), etc.-, its natural spaces presenting a wild appearance and its beaches, whereas the others pay attention mainly to the latter, which are adapted for tourism, and the attractive landscape of the natural spaces.

From the results commented upon, we can deduce three converging strategies in one destination image: $i$ ) joint and participatory policy. $i$ ) economically interested selection and iii) a conglomerate of initiatives. Tourism policies based upon sustainability and which attempt to meet the needs of present-day tourists without compromising the future, are increasingly and insistently recommending the first of these options. This one is more likely to provide the destination area with tools for responding to changes on the market without seriously altering the social and economic structures. Furthermore, it effectively prevents day-do-day goods and spaces from being changed into representation products, and attempts to adjust the attraction of an area's attributes and resources (decision-making effect) while avoiding cultural losses (Santana Talavera [13]). We found no valid references of this strategy in Fuerteventura in the creation of the image. 
Table 5: Elements of Fuerteventura's heritage employed by the Administration and other promoters to project the island's tourism image ( $\mathrm{N}$ represents in an undifferentiated manner the total of brochures or websites falling in the categories indicated according to the promoter (see previous tables).

\begin{tabular}{|c|c|c|c|c|}
\hline Elements & \multicolumn{2}{|c|}{ Administration } & \multicolumn{2}{c|}{ Rest } \\
\hline & $\mathrm{N}(32)$ & $\%$ & $\mathrm{~N}(152)$ & $\%$ \\
\hline Mills, agric. traditional & 11 & 34.38 & 12 & 7.89 \\
\hline Handicrafts & 9 & 28.13 & 4 & 2.63 \\
\hline Gastronomy & 7 & 21.88 & 12 & 7.89 \\
\hline Festivities & 3 & 9.38 & 2 & 1.32 \\
\hline Livestock & 4 & 12.50 & 7 & 4.61 \\
\hline Fishing & 1 & 3.13 & 5 & 3.29 \\
\hline Natural spaces & 19 & 59.38 & 29 & 19.08 \\
\hline Unique structures & 7 & 21.88 & 13 & 8.55 \\
\hline Tourist beaches & 10 & 31.25 & 42 & 27.63 \\
\hline Sculptures & 6 & 18.75 & 0 & 0.00 \\
\hline Archaeological localities & 3 & 9.38 & 0 & 0.00 \\
\hline None & 0 & 0.00 & 7 & 4.61 \\
\hline
\end{tabular}

In the interviews conducted, local officials do comment on the need for the local population to participate in these and other aspects, but this is not backed by the attitude of these populations. This may contribute to giving rise to a nonneutral selection of products related with the natural environment or culture (beaches, landscapes in unique arid areas on the island, museums, mills, etc.). This involves extracting them from their sociocultural context and presenting them as 'authentic', in an anachronic manner (very few mills are still used), attempting to instil the idea of an unforgettable and unique experience (Markwell [18]) for the consumer while promoting its repeatable and standardized use for all tourists.

The second strategy for constructing image directly involves the business world. This is more evident in the case analysed. It is normally determined by specialists and applied to destinations in an intermediate phase of its life cycle (Agarwal [19]; Baum [20]; Butler [21]). The island of Fuerteventura is in this situation at present. It is not a case of important innovations, but rather alterations and additions to previous campaigns. In general terms, an attempt is made to maintain competitive advantages while modifying the attributes of resources and products, combining activities and introducing specific services and structures. It is a continuist attitude, that attempts to avoid risks and drastic changes in the destination's image and which is very coherent with the main motivation of the current tourists (Table 1, Figures 2 and 3). It corresponds to the expectations of potential visitors because determined essential desires and fantasies in their motivations tend to be symbolized (Markwich [22]). Schouten [23] states that a good interpretation is based on connections made with ideas 
and experiences that are already familiar, and on visitors' increased curiosity. This form of diversification of the constructed image can easily be redirected towards participatory strategies when applied to small destinations or territorially coherent tourist areas, but it meets with serious operative problems and conflicts of interests when large, heterogeneous consolidated areas are involved.

The third strategy lies in the adaptation of the projected image to the 'territorial realities' according to their target groups (residents and tourists), offering an aesthetic 'acquisition' and an emotional experience in an extremely short space of time. This, combined or not with participation, occurs with the attempt to strategically redirect the island as a destination by the island's Administration (Cabildo) and some town councils. This type of constructed image allows the entry of multiple individualized products with or without cover of the brand or identity of the destination and, furthermore, responds to national and international compromises by the Administration to preserve and disseminate nature and cultural heritage.

This strategy, however, might suffer from the so-called 'indifference factor' or disinterest that a potential client could show in relation to the 'quality' attributed to nature and culture as opposed to determined products considered to be basic to the offer. Thus, although planners at the destination trust in their own series of amenities, the potential of these as a resource and their capacity to differentiate the destination, the client might clearly be pre-directed towards consumption of other products or resources and not appreciate any of this at all. The image of Fuerteventura has been stereotyped through insistence on climate and beaches, supported both by the promotional campaigns of the $90 \mathrm{~s}$ and the start of the new century, and by indirect marketing (non-tourist documentaries, sports news, intentional weather reports, word of mouth among tourists, etc.) Consequently, the directionality of the offer by the administrations and the interest by some conservationists in the sought-after cultural tourism (Pineda et al. [24]), based on efforts to give priority to the ethnographic-ethnic values present ('living culture'), relevant monumental or archaeological natural spaces, may prove to be unfruitful.

\section{Conclusion}

The island of Fuerteventura's tourism image is seen to be made up of a set of initiatives that are more or less compatible and which tend to values the destination's attributes as resources, imagining the demand for them. The decision by Fuerteventura's local administrations to opt for an image adapted to cultural and nature tourism stereotypes can be seen as a strategy aimed at restructuring and differentiating the destination. This $i$ ) obviates current demand as this is considered to be guaranteed or even undesirable. $i i$ ) it is aimed at hypothesised market segments and iii) it has not been preceded by collaborative processes with other agents entrusted with promoting image, who focus their projection on a classical demand for the destination.

In practice, the above mentioned circumstances can constitute serious confusion. At present on the international tourism market, a destination 
accommodating tourists motivated mainly by climate, beaches and price, as in Fuerteventura, can run into problems relating to competition. Other emerging destinations are in better conditions to provide excellent beaches and a good climate at competitive prices. Lin order to address this reality, there is a need to renovate the image, working to differentiate it, focusing on specific segments of demand.

A joint strategy and a wide and range of combined resources-products would compensate for the indifference of some visitors. Tourists would be attracted towards the destination by any of these resources-products and might end up consuming the same goods and services, although they present differences in their motivation and understanding of meanings. This diversification, presenting the heritage-culture-territory promoted as authentic and distinctive and facilitating rediscovery of the imagination, should make possible the mediumterm differentiation of the destination on the tourism market. This process involves maintaining the projected image of Fuerteventura by means of a specific stereotype and brand. The possibilities provided by Internet 2.0 -until recently merely an added value- can constitute a principal tool and the destination can be placed within this space. Production of contents presenting real references, a well-informed and lucid presentation of the environmental and cultural values of the island, as well as actual tourism services, can easily be provided to the pre-tourists (before the trip) and the tourists (at the destination).

\section{References}

[1] Baloglu, S. \& McCleary, K.W., A model of destination image formation. Annals of Tourism Research, 26(4), pp. 868-897, 1999.

[2] Gallarza, M.G., Gil Saura, I. \& Calderón García, H., Destination image. Towards a conceptual framework. Annals of Tourism Research, 29(1), pp. 56-78, 2002.

[3] Frías, D.M., Rodríguez, M.A. \& Castañera, J. A., Internet vs. travel agencies on pre-visit destination image formation: An information processing view. Tourism Management, 2007. In press.

[4] Um, S. \& Crompton, J.L., Attitude determinants in tourism destination choice. Annals of Tourism Research, 17, pp. 432-448, 1990.

[5] Gartner, W.C., Image Formation Process, Journal of Travel and Tourism Marketing, 2(2-3), pp. 191-215, 1993.

[6] Bigne, J.E., Sanchez, M.I. \& Sanchez, J., Tourism Images: Evaluation Variables and After Parchase Behaviour: Inter-Relationship, Tourism Management, 22, pp. 607-616, 2001.

[7] Baloglu, S. \& Brinberg, D., Affective Images of Tourism Destinations, Journal of Travel Research, 35(4), pp. 11-15, 1997.

[8] San Martín Gutiérrez, H., Rodríguez del Bosque, I. \& Vázquez Casilles, R, Análisis de la imagen en turismo mediante técnicas estructuradas y no estructuradas: implicaciones competitivas para destinos turísticos, Revista Asturiana de Economía, RAE, 35, pp.69-91, 2006. 
[9] Hunt, J.D., Images as Factor in Tourism Development, Journal of Travel Research, 13(3), pp. 1-7, 1975.

[10] Mercille, J., Media Effects on Image: The Case of Tibet, Annals of Tourism Research, 32(4), pp. 1039-1055, 2005.

[11] Franklin, A. \& Crang, M., The trouble with tourism and travel theory?, Tourist Studies, 1(1), pp. 5-22, 2001.

[12] Rodríguez Darias, A.J. Turismo en espacios naturales protegidos: imagen e impactos. El caso de Masca (Tenerife. Islas Canarias). In: Espina Barrio. A. (ed). Turismo. cultura y desarrollo, Ediciones de la Diputación de Salamanaca: Salamanca, España, pp. 235-247, 2008.

[13] Santana Talavera, A. Antropología do turismo. Analogías, encontros e relaçoes, Aleph: Sao Paulo, 2009.

[14] ISTAC, Encuesta de Alojamiento Turístico en Establecimientos Hoteleros y Apartamentos y Encuesta de Gasto Turístico, Instituto Canario de Estadística (ISTAC): Tenerife, Spain, 2000-2006, 2008.

[15] Glasser, B.G. \& Strauss, A.L. The Discovery of Grounded Theory: Strategies for qualitative research, Aldine: New York, 1967.

[16] Díaz, P., Rodríguez Darias, A.J \& Santana Talavera, A., El análisis de la imagen proyectada: una propuesta para normalizar folletos y web turísticos, Pasos. Turismo y Patrimonio Cultural, 2009. In press.

[17] Molina, A. \& Agueda, E., Tourism brouchures. Usefulness and image, Annals of Tourism Research en español, 8(2), PP. 315-338, 2006.

[18] Markwell, K., An intimate rendezvous with nature? Mediating the touristnature experience at three tourist sites in Borneo, Tourist Studies, 1(1), pp. 39-58, 2001.

[19] Agarwal, S., Restructuring seaside tourism. The Resort Lifecycle, Annals of Tourism Research, 29(1), pp. 25-55, 2002.

[20] Baum, T., Revisiting the Tourism Area Life Cycle Model - Is there an offramp?, In: Butler. R.W. (ed). The tourism area life cycle: conceptual and theoretical issues, Channel View Publications: Clevedon, UK, pp. 219-230, 2005.

[21] Butler, R.W., The concept of a tourism area cycle of evolution: implications for management resources, Canadian Geographer, 24(1)pp, 5-12, 1980.

[22] Markwich, M., Postales de Malta. Imagen, consumo, contexto. Annals of Tourism Research, 3(1), pp. 22-46, 2001.

[23] Schouten, F.F.J., Heritage as historical reality. In: Herbert. David T. (ed). Heritage. tourism and society. Tourism Leisure and Recreation, Mansell Publishing: London, pp. 21-31, 1995.

[24] Pineda, F.D., Hernández, S. \& De Nicolás, J.P., El reto de la conservación en Fuerteventura, Quercus, 232, pp. 80-81, 2005. 